\title{
Uso de imunomoduladores nas enfermidades infecciosas dos animais domésticos
}

\section{Use of immunomodulators in infectious diseases of domestic animals}

\author{
Camila Michele Appolinário ${ }^{1}$; Jane Megid $^{2}$
}

Resumo

\begin{abstract}
Imunomoduladores são substâncias que atuam no sistema imunológico conferindo aumento da resposta orgânica contra determinados microorganismos, incluindo vírus, bactérias e protozoários, mediante à produção de interferon e seus indutores. Existem muitas situações na medicina veterinária em que se torna desejável potencializar a resposta imune, principalmente quando se pretende aumentar a resistência às infecções e no tratamento de enfermidades imunossupressoras ou de doenças infecciosas multifatorias, ou seja, nas quais vários agentes estão envolvidos e devido a isso, dificilmente obtêm-se sucesso no emprego de tratamentos convencionais. Na medicina veterinária alguns imunomoduladores utilizados são interferons , interleucinas, Bacilo de Calmett-Guérin (BCG) e seus derivados, Propionibacterium acnes (Corynebacterium parvum), vacina bacteriana mista, PIND-ORF, Phosprenyl, Quillaja saponis, Bordetella pertussis, avridina e levamizol. O presente trabalho avalia a aplicação dos diferentes imunomoduladores na profilaxia e na terapêutica das doenças infecciosas dos animais domésticos.
\end{abstract}

Palavras-chave: Imunomoduladores, enfermidades infecciosas, animais domésticos

\begin{abstract}
Immunomodulators are substances that act in the immune system providing, increase of the organic answer against microorganisms, including virus, bacteria and protozoa, by inducing the production of interferon and its inducers. There are a lot of situations in veterinary medicine where it is usefull to potencialize the immune response of individuals, mainly when is desired to increase the resistance to infections and the treatment of immunossupressing or multifactorials infectious diseases. In veterinary medicine some of more used immunomodulators are interferons and interferon inducers, interleukines, Baccilus of Calmett-Guérin (BCG) and its derivated, Propionibacterium acnes (Corynebacterium parvum), mixed bacterial vaccine, PIND-ORF, Phosprenyl, Quillja Saponis, Bordetella pertussis, avridine and the levamizole. The present work review the available scientific literature, regarding the use of different immunomodulators in the prophylaxis and in the therapeutics of infectious diseases in domestic animals. Key words: Immunomodulators, infectious diseases, domestic animals
\end{abstract}

1 Médica Veterinária graduada na FMVZ_ UNESP, Botucatu, ex bolsista do CNPq, atual residente em Enfermidades Infecciosas dos Animais- Departamento de Higiene Veterinária e Saúde Pública - FMVZ-UNESP, Botucatu.

2 Correspondência para: Prof. Dra. Jane Megid. Enfermidades Infecciosas dos Animais - Departamento de Higiene Veterinária e Saúde Pública - FMVZ-UNESP, Botucatu. Email: jane@fmvz.unesp.br.

* Autor para correspondência 


\section{Introdução}

O controle das infecções nos animais é constituído pela imunidade ativa (antígeno-específico) e passiva (antígeno-independente). O estado de aumento da proteção-inespecífica contra agentes invasores, opostamente à imunidade, é conhecido como paraimunidade ou "mecanismo de defesa não-imune" (CASTRUCCI et al., 1994).

As células responsáveis por ambos os mecanismos de defesa também variam. O sistema imune específico é composto basicamente por linfócitos $\mathrm{T}$ e $\mathrm{B}$ que quando ativados resultam na imunidade específica celular e humoral. A paraimunidade é mediada principalmente por neutrófilos polimorfonucleares, macrófagos e células natural killer (NK), que ao contrário dos linfócitos $\mathrm{T}$ e B, não possuem memória imunológica, mas agem nas fases precoces da infecção; existe ainda os fatores humorais constituintes da imunidade -inespecífica como os interferons (IFN), as interleucinas (IL) e o fator de necrose tumoral (TNF) (CASTRUCCI et al., 2000).

A paraimunidade pode ocorrer sob condições naturais pelo contato do organismo com o agente causador de infecção ou pode ser induzida artificialmente pela administração de imunomoduladores. Os imunomoduladores variam de acordo com a sua origem, seu modo de ação e a maneira como são utilizados; ao contrário dos adjuvantes, que obrigatoriamente têm de ser administrados em conjunto com o antígeno para potencializar uma resposta imune, os imunomoduladores podem ser administrados independentemente (TIZARD, 2002).

A descoberta da imunomodulação ocorreu durante a campanha mundial de erradicação da varíola através da vacinação com uma vacina de vírus atenuado, descoberta por Edward Jenner, no século 18. Após as vacinações em massa da população, começou-se a observar os efeitos benéficos e colaterais que esta vacina exercia sobre os indivíduos.
Foi portanto apropriado a escolha do termo imunomodulação para os efeitos da vacina contra a varíola, pois estes poderiam estar relacionados tanto à imunoestimulação como à imunossupressão (BAXBY, 1981). Na literatura recente, encontramse referências de pacientes (humanos ou animais) acometidos por enfermidades bacterianas que apresentaram regressão de processos neoplásicos concomitantes (VAN KAMPEN, 1997). Também há relatos de reações benéficas pós-vacinais como a resolução repentina de determinadas doenças, além de uma melhora substancial nos casos de herpes, papilomatose, doenças dérmicas crônicas e infecções das vias aéreas superiores. (HARTMANN et al., 1998).

Atualmente os imunomoduladores são utilizados na medicina humana para o tratamento de algumas enfermidades como neoplasias, imunossupressão de causas variadas, artrite, asma e outras enfermidades inflamatórias. Na medicina veterinária existem situações em que se torna desejável potencializar a resposta imune, entre estas situações podemos citar o incremento da resistência às infecções e o tratamento de enfermidades imunossupressoras ou infecciosas de origem multifatorial (CASTRUCCI et al., 1994; TIZARD, 2002).

O presente trabalho avalia o uso de imunomoduladores na terapêutica de doenças infecciosas, bem como cita o uso destes em enfermidades de caráter não infeccioso.

\section{Revisão de Literatura}

Imunomoduladores são substâncias que atuam no sistema imunológico conferindo, entre outros, aumento da resposta orgânica contra determinados microorganismos, incluindo vírus, bactérias e protozoários, mediante principalmente à produção de interferon e seus indutores (VANSELOW apud MEGID, 2001). A origem dos imunomoduladores é muito variada, pode incluir substâncias farmacológicas sintéticas, produtos microbianos e plantas medicinais (BLECHA, 2001). 
Os imunomoduladores podem ser ativos específicos, ativos inespecíficos e passivos. A maior parte destes agentes proporciona um incremento ativo e não-específico da resposta imune dos indivíduos (SPINOSA et al., 1999). Alguns destes são: interferons e indutores de interferon, as interleucinas, o bacilo de Calmett-Guérin (BCG) e seus derivados, o Propionibacterium acnes (Corynebacterium parvum), vacina bacteriana mista, PIND-ORF, Phosprenyl, Quillaja saponis, Bordetella pertussis, componentes da parede de Staphylococcus aureus, avridina e o levamizol.

Segundo Spinosa et al. (1999), os imunoestimuladores possuem ações específicas, como por exemplo os interferons e indutores de interferons que inibem ou estimulam a produção de proteínas, induzem receptores para Imunoglobulinas do tipo $\mathrm{G}$ ( $\mathrm{IgG}$ ) e Fixadores de Complemento (FC) em monócitos e macrófagos além de estimularem macrófagos e células (NK). As interleucinas possuem ação mitógena para os timócitos, estimulando a resposta de fase aguda e a proliferação e ativação de linfócitos $\mathrm{T}$ e $\mathrm{B}$ e, assim como interferons e indutores de interferon, estimulam macrófagos e células NK. O Bacilo de CalmettGuerrin (cepa viva atenuada de Mycobacterium bovis) e seus derivados ativam células $\mathrm{T}$ e $\mathrm{B}$, liberando linfocinas e recrutando macrófagos resultando em ação granulomatosa.

Dentre os principais imunomoduladores utilizados, ou que ainda estão em fase de pesquisas para futura utilização na terapêutica das enfermidades dos animais domésticos podemos citar o Propionibacterium acnes, BCG, Interferon, CpGODN, DHEA, PIND-ORF e Acemanana.

\section{Propionibacterium acnes (P. acnes)}

Propionibacterium acnes é uma bactéria Grampositiva, residente natural das glândulas sebácias do folículo piloso da pele humana, vive em ambiente de anaerobiose, crescendo de maneira mais eficaz neste, no entanto, algumas cepas são aerotolerantes.
Também é conhecido como Corynebacterium parvum, devida a sua semelhança morfológica e organizacional (BRANNAN, 2005).

Como todas as bacterinas promove a formação de anticorpos quando administrada como uma suspensão inativado sendo rapidamente fagocitado pelos macrófagos, estimulando a síntese de citocinas. Possui uma atividade complexa, já que estimula os macrófagos e a resposta de anticorpos aos antígenos timo-dependentes, mas possui efeito variado na resposta aos antígenos timo-independentes. Esta bactéria possui ação imunoestimulante geral que leva a uma potencialização da atividade antibacteriana e antitumoral (TIZARD, 2002). Mais especificamente, aumenta a produção de linfócitos $\mathrm{T}$ e $\mathrm{B}$, aumentando, portanto, a imunidade mediada por células, facilitando a função de macrófagos e células NK (SPINOSA, 1999).

Propionibacterium acnes foi utilizado por Weiss e Cox (1990) em gatos, nos quais foram avaliadas a eficácia dos interferons (IFN) e do $P$. acnes isoladamente ou associados contra a infecção experimental do vírus da peritonite infecciosa felina (PIF). A administração profilática e terapêutica de altas ou moderadas doses de diferentes interferons ou $P$. acnes não reduziram significantemente a mortalidade dos gatos tratados e não-tratados. $\mathrm{O}$ tempo de sobrevivência dos gatos tratados com IFN isoladamente ou associado ao P. acnes foi muito maior do que dos gatos não-tratados, mesmo todos os grupos recebendo altas doses letais da cepa virulenta do vírus PIF.

Davis, Rush e Blecha (2003) relataram o uso do $P$. acnes na profilaxia das inflamações pulmonares crônicas em eqüinos. Nos estudos realizados com estes animais tratados houve um aumento de IFN, NK e células mononucleares da circulação periférica. Estes resultados sugerem que a ação imunomoduladora do $P$. acnes se dá pelo aumento da produção de IL-1, IFN e NK.

Flaminio, Rush e Shuman (1998) avaliaram a atividade fagocítica, a expressão fenotípica das subpopulações de linfócitos e a resposta mediada por 
linfocinas induzidas por P. acnes, no tratamento de doenças pulmonares em cavalos. A utilização de uma série de três injeções de $P$. acnes demonstrou a propriedade imunoestimulatória e imunomoduladora deste, caracterizadas por um aumento da expressão de CD4, concentração de linfócitos no sangue e no fluido da lavagem broncoalveolar, aumento da atividade não fagocítica dos leucócitos e decréscimo celular no pulmão.

Panangala et al.(1986) testaram a eficácia da imunomodulação do $P$. acnes associada à vacina para Brucella abortus B-19, em cobaios. Um grupo recebeu P. acnes associado à vacina enquanto o outro recebeu apenas a vacina. Os animais foram desafiados com B. abortus, sacrificados após o desafio e necropsiados. Os animais vacinados e que receberam o imunomodulador, apresentaram uma menor quantidade de Unidades Formadoras de Colônia (CFU) da semeadura de baço em comparação aos animais que apenas foram vacinados. Isto indica que o $P$. acnes administrado simultaneamente a vacina foi capaz de aumentar a resposta imune nestes animais, devido a maior ativação de macrófagos, ao aumento dos mecanismos citolíticos mediados por células-T ou devido ao aumento de ambos os mecanismos.

Glasgow et al. (1977) realizaram um experimento em que tratavam camundongos com P.acnes e outros imunomoduladores como o BCG de 7 a 10 dias antes de serem desafiados com diferentes tipos virais, entre estes o Herpesvirus hominis tipo 2, vírus da encefalomiocardite e citomegalovírus. Os bons resultados sugerem que a imunomodulação proporcionada por estes agentes possa ser uma maneira de aumentar a resistência do hospedeiro contra infecções virais.

Trabalhos realizados por Megid et al. (1998) com P. acnes e outros imunomoduladores (Avridina e BCG) associados à vacina Fuenzalida \& Palacios em camundongos infectados e tratados pósexposição, demostraram taxa de sobrevivência superior em animais que receberam $P$. acnes associado à vacina Fuenzalida \& Palacios, quando comparada aos grupos de animais que receberam outros imunomoduladores como Avridina e BCG.

Becker et al. (1989), avaliaram a eficácia do $P$. acnes no tratamento de piodermite. Os animais receberam $P$. acnes por um período de 12 semanas associado ao uso de antibiótico, de uso preferencial do veterinário. Do grupo teste $80 \%$ apresentaram remissão completa ou melhora clínica significativa durante o tratamento, enquanto no grupo controle, tratado apenas com antibiótico, apenas 38\% apresentaram remissão ou melhora clínica.

Cox (1988) demonstrou a eficácia do P.acnes no tratamento do quadro de anemia de gatos positivos para o vírus da Leucemia Felina (FeLV). Obteve-se um aumento evidente nos eritrócitos e leucócitos após a terapia com P.acnes, enquanto o grupo não-tratado continuou anêmico e com baixa contagem de leucócitos.

Megid et al. (2001) obtiveram sucesso no tratamento de Papiloma oral em cães de diferentes idades, através de aplicações semanais de P.acnes. Após a quinta aplicação observou-se completa regressão dos papilomas. Hall et al. (1994), também apresentaram resultados positivos no uso do $P$. acnes no tratamento de Papiloma bovino, com aplicações intralesionais. Os animais apresentaram regressão completa das lesões em 15 semanas.

O P. acnes foi utilizado com sucesso na terapia de endometrites, osteomielite em eqüinos e no tratamento de feridas. (VAN KAMPEN, 1997).

\section{BCG (Bacilo de Calmette-Guerrin)}

O BCG constitui-se de uma cepa vacinal atenuada do Mycobacterium bovis. É um dos mais potentes potencializadores da síntese de citocinas, devido a ativação de macrófagos, mas também exerce uma potencialização generelizada da fagocitose, das respostas mediadas por células $B$ e células $T$ (TIZARD, 2002).

Segundo Van Kampen (1997) o BCG vem sido usado com sucesso no tratamento de diarréias causadas por Escherichia coli em bezerro. Os 
animais tratados apresentam melhora nos sintomas clínicos, além de haver diminuição na taxa de mortalidade.

Comack et al. (1991) utilizaram BCG em cavalos que apresentavam Complexo Respiratório Eqüino. Extrato super-purificado da parede do BCG foram aplicadas de forma intravenosa; o resultado foi o completo restabelecimento, em 7 dias, do quadro clínico de $82 \%$ dos animais tratados, enquanto no grupo não tratado, apenas $33 \%$ se restabeleceram.

Knottenbelt et al. (2000) utilizaram o BCG comparativamente a outros protocolos terapêuticos no tratamento de sarcóide periorbital em cavalos. Neste estudo de 445 casos de sarcóide periorbital, utilizou-se diferentes recursos terapêuticos como a excisão cirúrgica da massa, criocirurgia, imunomodulação com Bacilo de Calmette-Guerrin (BCG), aplicação tópica de agente citotóxico e radiação. $\mathrm{O}$ tratamento com radiação mostrou-se o mais eficaz com $100 \%$ de resolução dos casos, mas apresenta desvantagens, como aplicação difícil e custo elevado. Em contrapartida, o tratamento com infiltração intranodular de BCG demonstrou bons resultados (69\% de resolução dos casos) e deve ser considerado como uma opção de tratamento para esta enfermidade que quando não tratada adequadamente tem alto índice de recorrência, geralmente de forma mais agressiva, de crescimento rápido e de infiltração extensa.

\section{PIND-ORF (Baypamun $\AA$, Bayer).}

PIND-ORF, comercialmente conhecido como Baypamun ${ }^{\circledR}$ é um imunomodulador constituído da estirpe viral D1701 do Parapoxvírus que acomete os ovinos, e como outros imunomoduladores, ativa os mecanismos imunes antígeno-independentes, como a produção de interferon pelas células mononucleares infectadas por vírus; diferenciação de células imaturas em células maduras e proliferação dos linfócitos.

Em estudos realizados por Hartmann et al. (1998), o Baypamun ${ }^{\circledR}$ foi utilizado no tratamento da
Leucemia Viral Felina (FeLV), doença de caráter letal, em gatos naturalmente infectados. Nestes estudos, os animais diagnosticados como FeLV positivos através do método sorológico de ELISA, foram separados em dois grupos distintos, sendo um grupo tratado por um período de sete semanas com imunomodulador, segundo as instruções do fabricante, e o outro grupo tratado com placebo. Embora não estatiscamente significante, os animais que receberam Baypamun ${ }^{\circledR}$ apresentaram uma concentração de antígenos menor do que o grupo placebo, além de apresentarem melhora no quadro clínico geral. Este resultado entra em conflito com os resultados obtidos em experimentos realizados por outros autores, que afirmaram conseguir de 80 a $100 \%$ de conversão sorológica dos animais infectados por FeLV que receberam tratamento com Baypamun ${ }^{\circledR}$ (HORBER; MAYR apud HARTMANN et al., 1998).

Doenças respiratórias de origem viral podem ter conseqüências econômicas importantes num rebanho bovino, devido à queda de produção e óbito dos animais devido à complicações respiratórias, o que pode ocorrer com animais de todas as idades. A mais comum destas enfermidades respiratórias é a Rinotraqueíte Infecciosa Bovina (IBR), cujo agente causador é o Herpesvírus Bovino tipo-1 (BHV-1).

Em trabalhos realizados por Castrucci et al. (2000) verificou-se a efetividade do imunomodulador Baypamun ${ }^{\circledR}$ em limitar a disseminação do HBV-1. Bovinos infectados experimentalmente com o HBV1 foram divididos em grupos de animais tratados e não-tratados com imunomodulador. Os animais infectados e que receberam Baypamun ${ }^{\circledR}$ apresentaram sinais clínicos clássicos constituídos de hipertermia, tosse, secreção nasal e ocular, perda de peso e apatia menos severos em comparação ao grupo não-tratado. No mesmo experimento animais saudáveis coabitaram com um animal infectado, sendo que apenas metade dos animais saudáveis receberam Baypamun ${ }^{\circledR}$; como resultado, os animais não-tratados desenvolveram a sintomatologia clássica e severa da enfermidade, enquanto os animais que receberam imunomodulador foram apenas parcialmente afetados (CASTRUCCI et al., 1994). 
Bovinos infectados experimentalmente com BHV-1, após alguns dias, apresentaram a forma clássica da Rinotraqueíte Infecciosa. Permitiu-se que estes animais enfermos, permanecessem em contato com animais saudáveis, sendo que todos os animais saudáveis receberam tratamento com Baypamun ${ }^{\circledR}$ em diferentes protocolos de administração e em diferentes tempos. Todos os animais tratados demonstraram poucos sinais clínicos da doença, enquanto os animais tratados por quatro dias consecutivos com o imunomodulador não apresentaram qualquer sinal clínico (CASTRUCCI et al., 1998).

Verificando a efetividade da ação imunomoduladora associada à vacinação Castrucci et al. (1996), vacinaram um animal um mês antes de entrar em contato com animais infectados e que apresentavam os sinais clínicos da doença. Outros animais receberam a vacina, associada ou não ao imunomodulador, assim que entraram em contato com os animais infectados. Os que apenas tinham sido vacinados, apresentaram a forma clássica da doença, enquanto os animais vacinados e que receberam Baypamun ${ }^{\circledR}$ não desenvolveram a forma clínica da enfermidade.

Nesta série de experimentos realizados, os animais tratados com Baypamun ${ }^{\circledR}$ tiveram uma redução significativa na disseminação viral. Portanto, os resultados demostraram que o uso de indutores de imunidade associados a vacinação poderiam reduzir as perdas econômicas e limitar a disseminação do vírus HBV-1 e conseqüentemente a redução do aparecimento da Rinotraqueíte Infecciosa Bovina nas propriedades.

Em trabalho realizado por Kyriakis et al. (1998), Baypamun ${ }^{\circledR}$ foi utilizado como agente profilático em duas enfermidades que acometem leitões no período do pós-desmame, Síndrome Diarréica Pós-Desmame (PWDS) e Síndrome Debilitante Suína (WPS). Duas enfermidades comuns na produção de suínos e que são induzidas por fatores estressantes ocorridos no desmame precoce, além de complicações ocasionadas por agentes oportunistas. Como principal agente oportunista encontra-se Escherichia coli.(E. coli) Os leitões recém-desmamados foram separados em grupos de tratados e não-tratados com Baypamun ${ }^{\circledR}$. Os resultados demonstraram que os animais tratados com imunomodulador apresentaram uma performance melhor em todos os parâmetros analisados (severidade da PWS, mortalidade, parâmetros de crescimento e presença de patógenos nas fezes) comparativamente aos animais do grupo controle. Concluiu-se então, que a estimulação do sistema imune não-específico dos leitões através do uso de imunomoduladores, pode ser útil na prevenção do aparecimento da PWS e PWDS nas criações comerciais de suínos.

Winnicka et al. (2000), utilizaram o Baypamun ${ }^{\circledR}$ em cabras, antes e após a indução de imunossupressão através do uso de dexametasona. A aplicação de Baypamun ${ }^{\circledR}$ antes ou após a imunossupressão ocasionou um aumento significativo nas células T do tipo CD2+, CD4+ e CD8+. Os resultados demonstraram que a aplicação de Baypamun ${ }^{\circledR}$ a fim de aumentar a resposta imune inespecífica, é recomendada em casos de imunossupressão.

\section{CpG-ODN e Vitamina D 1a,25(OH)2D3}

Um metabólito ativo da vitamina D 1a,25(OH)2D3, é um hormônio esteroidal que atua no receptor nuclear para a vitamina D3 influenciando na transcrição de inúmeros genes. Em camundongos, tem ação imunomoduladora, principalmente no aumento da produção e excreção de $\operatorname{IgA}$ e IgG pela lâmina própria intestinal e pulmões; é classificado como Th-2 imunomodulador (DAYNES; ARANEO, 1994).

O CpG-ODN (cytosine-phosphodiester-guanine oligodeoxynucleotide) constitui-se de um conjunto de seis pares de base de DNA, sendo que um destes pares é o CpG-desmetilado. Sabe-se que o DNA bacteriano é rico nesta configuração de pares de base. Estudos recentes demonstraram que o sistema imune dos mamíferos é estimulado por este padrão de pares de base. Qualquer DNA bacteriano ou até 
mesmo oligonucleotídeos sintéticos que expressem o CpG estimulam rapidamente as células $\mathrm{B}$, células $\mathrm{T}$, células NK, alem de estimular a proliferação dos macrófagos e a produção de citocinas, incluindo interferons (IFN-3) e interlucinas (IL-12, IL-6, IL18). A rápida indução da resposta imune inespecífica, incluindo a produção de citocinas relacionadas a Th1 , ocasiona um incremento precoce no combate a disseminação de agentes intracelulares (ELKINS et al., 1999).

Como já citado anteriormente, a Escherichia coli é um dos principais agentes oportunistas da PWDS, resultando em grandes perdas econômicas nas criações comerciais. A infecção neonatal pode ser prevenida através da ingestão de colostro rico em anticorpos de porcas vacinadas. No entanto, nenhuma vacina está disponível para a PWD, pois a ocorrência desta enfermidade depende de outros fatores, como a mistura dos animais, a mudança de temperatura ambiental, a umidade, a dieta e o declínio da imunidade colostral que ocorre no período do desmame. A imunidade protetora constituída de anticorpos, principalmente IgA presente no intestino delgado, impede a adesão da E. coli. Em trabalho realizado por Van Der Stede et al. (2003) leitões foram imunizados com F4 (fímbria produzida pela E. coli) durante o período de lactação associado a administração de dois imunomoduladores, 1a,25(OH)2D3 e CpG-ODN com o objetivo de incrementar a proteção contra $E$. coli, e após determinado período foram desafiados com este enteropatógenos. Os resultados demonstraram que a imunização dos leitões lactentes associada a suplementação com 1a,25(OH)2D3 reduziu a excreção de $E$. coli nas fezes, relacionada a uma maior produção de IgA na mucosa intestinal; os animais que receberam CpG-ODN apresentaram uma proliferação significativa dos linfócitos T. Estes resultados demonstram que tanto o 1a,25(OH)2D3 como o CpG-ODN possuem o potencial de incrementar as vacinas de uso veterinária contra enteropatógenos.

Elkins et al. (1999) utilizaram o CpG-ODN para avaliar a eficácia deste imunomodulador na prevenção de infecções por agentes bacterianos intracelulares. Os animais receberam Cpg-ODN sintético ou de origem bacteriana, três dias antes de serem desafiados com doses consideradas como letais, de Listeria monocytogenes e Francisella tularensis. Como resultado, os animais que receberam CpG-ODN já apresentavam proteção eficaz contra a infecção, 3 dias após o tratamento e esta persistiu por mais de 2 semanas. Todos os animais sobreviveram, mesmo após serem desafiados com doses letais das bactérias supracitadas, ratificando as observações referentes à ação imunomoduladora do CpG-ODN devido a atividade não-específica de linfócitos e a imunorregulação de citocinas. Pode-se concluir, que o $\mathrm{CpG}-\mathrm{ODN}$ pode ser utilizado isoladamente na rotina clínica, devido aos seus benefícios, ou associado à vacinas, a fim de contribuir para o desenvolvimento de uma resposta imune maior e mais duradoura.

Em trabalho realizado por Lowry et al. (2005), o CpG-ODN foi utilizado in vitro, na estimulação de leucócitos e in vivo, na proteção contra Salmonella enteritidis (SE). O CpG-ODN foi administrado em frangos de um dia de vida, seguido do desafio oral com SE. Houve uma redução significativa da invasão dos órgãos pela SE nos animais tratados com este imunomodulador. Uma menor taxa de mortalidade também foi observada em frangos que apresentavam peritonite aguda, ocasionada pela SE. Este estudo evidenciou que o CpG-ODN tem ação estimulatória sobre o sistema imune inespecífico, bem como incrementa a resistência à infecções por patógenos intestinais em frangos recém-nascidos.

Ainda sobre o uso de CpG-ODN em aves recémnascidas, Gomis et al. (2004), utilizaram este imunomodular com o objetivo de investigar sua ação nos casos de septicemia ocasionada por E. coli. Frangos de dois dias de idade e ovos embrionados de 18-19 dias foram inoculados com uma dose de CpG-ODN. Após três dias de terem recebido imunomodulador, os frangos foram desafiados com E.coli e observados por um período de sete dias. A taxa de sobrevivência do grupo tratado foi 
significativamente maior em comparação a do grupo controle, que variou de 0 a $20 \%$. A contagem de bactéria nos sacos aéreos destas aves, também foi significativamente menor nos animais que receberam o CpG-ODN, em comparação aos animais do grupo controle. Os resultados demonstraram que o $\mathrm{CpG}$ ODN, exerce proteção sistêmica efetiva contra a Escherichia coli, em frangos.

Zimmermann et al. (1998) utilizaram o CpG-ODN para avaliar seu potencial efeito protetor e curativo em camundongos infectados experimentalmente com Leishmania major. Os animais foram inoculados com formas promastigotas do protozoário e depois receberam tratamento com $\mathrm{CpG}-\mathrm{ODN}$. Os animais do grupo controle, desenvolveram a leishmaniose de forma severa e tiveram de ser sacrificados após 8 semanas pósinfecção, em comparação, os animais tratados desenvolveram resistência. Inicialmente, houve um aumento no membro inoculado seguido de uma diminuição das lesões, que posteriormente tornaram-se estáveis. Mesmo sofrendo reinfecção, após 10 semanas da primeira inoculação, os animais tratados com CpGODN apresentaram apenas um pequeno aumento na circunferência do membro inoculado. Estes resultados demonstraram o potencial terapêutico do CpG-ODN nesta enfermidade de caráter letal.

Estudos vêm sendo realizados, sobre o uso do CpG-ODN na profilaxia e terapêutica de doenças virais, alérgicas e tumores em cães (KURATA et al., 2004). Outros trabalhos se destinam ao uso deste imunomodulador associado à vacinas contra as mais diversas enfermidades, humanas e animais, devido ao seu poder de aumentar a resposta imunológica quando utilizado com o adjuvante. Dentre estas associações podemos citar vacinas contra o vírus da influenza, vírus do sarampo, vírus da coriomeningite linfocítica, hepatite B, Bacillus anthracis e toxina tetânica (KLINMAN, 2004).

\section{DHEA e Levamisol}

DHEA (dehydroepiandrosterone) caracteriza-se como um hormônio esteroidal, produzido pela região cortical da glândula adrenal. Exerce ação imunomoduladora por ser um potente ativador tanto das células B como T, também exerce forte modulação na produção de citocinas próinflamatórias, TNF- \pm , IL-I e IL-6. Em trabalho realizado por Santos, Toldo e Prado Júnior (2005), o DHEA foi utilizado para avaliação de sua eficácia no tratamento de infecções por Trypanossoma cruzi. Ratos machos e fêmeas foram inoculados com a forma tripomastigota do parasita e receberam diariamente até o final do experimento uma dose de DHEA. Os resultados observados, demonstraram redução no número de parasitos no sangue, durante a fase aguda da infecção, o que significa um aumento da resistência dos animais tratados contra o parasito. $\mathrm{O}$ incremento da resposta imune ocasionado pelo DHEA nos animais tratados, sugere o uso deste imunomodulador como uma opção terapêutica útil, no tratamento da Tripanossomíase Americana.

O levamisol é um fármaco antihelmíntico de amplo espectro utilizado no tratamento de parasitose intestinal. Concomitantemente à ação antihelmíntica, este fármaco atua no sistema imunológico de maneira semelhante ao hormônio timopoietina, produzido no timo. Estimula a ação de células $\mathrm{T}$ e a resposta aos antígenos, potencializa a produção de interferons e aumenta a atividade fagocitária de macrófagos e neutrófilos, estimula a citotoxicidade mediada por células, a produção de linfocinas e a função das células supressoras. Os efeitos do levamisol são mais efetivos em animais com depressão da função de células $\mathrm{T}$, sendo que possui pouco ou nenhum efeito em animais com função normal destas células. (TIZARD, 2002).

$\mathrm{Na}$ prática veterinária, o uso de levamisol pode ser útil no tratamento de infeções crônicas, como a demodicose canina e no tratamento de doenças neoplásicas. (TIZARD, 2002).

\section{Interferons (IFN)}

Interferons são citocinas liberadas por células poucas horas após a infecção. Podem ser 
classificadas em dois tipos, I e II. O interferon secretado se liga a célula vizinha, resultando no desenvolvimento de uma resistência à infecção viral dentro de poucos minutos a algumas horas. Os interferons estimulam a produção de muitas proteínas, algumas delas possuem atividade antiviral. Embora os vírus vivos e inativados sejam os principais estimuladores da produção de interferons, estes também podem ser induzidos por meio de endotoxinas bacterianas. Acreditava-se anteriormente que a administração exógena de interferons deveria inibir a replicação viral, bem como estimular as funções das células do sistema imunológico e assim se constituir uma potente droga contra infecções virais. Após vários estudos, concluiu-se que altas doses de interferons são tóxicas e causam efeitos colaterais indesejáveis, além de demonstrarem ser agentes antivirais pouco eficientes. (TIZARD, 2002).

Hartmann et al. (1999), administrou a droga antiviral AZT e IFN $\alpha$ (interferon alfa) de maneiras isoladas ou associadas, no tratamento de gatos positivos para FeLV. Nenhum dos tratamentos utilizados tornou os animais sorologicamente negativos.

Associações entre interferons e outros imunomoduladores, também tem sido feitas na tentativa de tratamento de gatos FeLV- positivos. McCaw et al. (2001) utilizaram IFN $\alpha$ de forma associada ou isolada a proteína A de estafilococo em gatos clinicamente doentes por FeLV., e observou que nenhum dos tratamentos utilizados resultou na negatividade sorológica dos animais.

\section{Acemanana}

Acemanana é um carboidrato complexo, derivado da planta Aloe vera. É um potencializador da síntese de citocinas com atividades antivirais e antitumorais, ativador de macrófagos e da imunidade celular. Este imunomodulador é utilizado no tratamento de FeLV e nos casos de fibrossarcomas em cães e gatos, no encapsulamento da massa tumoral antes da sua retirada cirúrgica. Tem sido utilizado de forma efetiva no tratamento de sarcóide eqüino e na cicatrização de feridas (VAN KAMPEN, 1997; TIZARD, 2002).

\section{Outros Imunomoduladores}

Lin et al. (1993) avaliaram um novo complexo imunoestimulatório contra a raiva. Este complexo, o PICK Ca, amplamente usado na China contra doenças humanas, foi testado na profilaxia experimental da raiva. Os autores observaram a ação protetora em ratos contra infecções periféricas para ambas as cepas rábicas testadas, a fixa e a de rua. Adicionalmente presenciaram aumento da atividade protetora da vacina contra a raiva, evidenciada antes e depois da infecção pelo vírus. O produto demonstrou incrementar as respostas imunes nãoespecíficas, como também as específicas, incluindo a produção de anticorpos.

Danilov et al. (1996) comprovaram a eficácia do Phosprenyl como droga anti-viral e com atividade imunomoduladora. O produto foi altamente eficaz contra uma série de viroses incluindo HIV in vitro, e na raiva, em modelos experimentais in vivo. Phosprenyl é utilizado como um recurso terapêutico efetivo no tratamento de enfermidades como a cinomose, hepatite e enterites.

Chavali, Barton e Campbell. (1988) evidenciaram o efeito imunopotenciador das Quillaja saponis na vacinação anti-rábica em camundongos, em protocolos vacinais pré e pós-expositivos. Em todos os protocolos, houve um aumento significante dos anticorpos específicos contra a raiva (todas as Igs) e camundongos que receberam saponina três dias antes, apresentaram aumento dos níves de $\mathrm{IgG}$, utilizando doses vacinais menores do que as padrões.

Winters et al. (1985) testaram a vacina de lipopolissacarídeos extraídos de Bordetella pertussis. Estes lipopolissacarídeos apresentaram efeitos antivirais contra o vírus rábico, vírus da encefalomiocardite, e o Herpes simplex.

Segundo Labro (1998), alguns trabalhos estão sendo realizados no uso profilático de antibióticos como imunomoduladores em pacientes propensos a desenvolver doenças infecciosas. A Cefodizime mostrou ser eficaz tanto profilático como terapeuticamente em animais acometidos por 
patógenos resistentes, como Candida albicans, Plasmodium spp, Toxoplasma gondii $e$ Staphylococcus aureus resistentes a metaciclina e até mesmo em animais imunossuprimidos. Este agente antimicrobiano atua como restaurador da função dos fagócitos, além de diminuir a produção de vários citocinas pró-inflamatórias.

\section{Conclusão}

A imunomodulação é ainda um vasto campo para a pesquisa em medicina veterinária. Em vista de todos os trabalhos apresentados nesta revisão da literatura científica, podemos concluir que os imunomoduladores podem ser recursos valiosos, na profilaxia e na terapêutica das doenças infecciosas, bem como de outras enfermidades de caráter nãoinfeccioso.

\section{Referências}

BAXBY, D. Jenner's Smallpox Vaccine. London: Morrison and Gibb, 1981.

BECKER, A. M.; JANIK, T. A; SMITH, E. K.; SOUSA, C. A.; PETERS, B. A. Propionibacterium acnes immunotherapy in chronic recurrent canine pyoderma. An adjunct to antibiotic therapy. Journal of Veterinary Internal Medicine, Lawrence, v.3, n.1, p.26-30, Jan./Mar. 1989.

BLECHA, F. Immunomodulators for prevention and treatment of infeccious diseases in food-producing animals. Veterinary Clinics of North America-Food Animal Practice, Philadelphia, v.17, n.3, p.621-633, Nov. 2001.

BRANNAN, Chris. Propionibacterium acnes. Disponível em:<http://web.umr.edu/ microbio/BIO221_1998/ P_acnes.html>. Acesso em: 25 maio 2005.

CASTRUCCI, G.; FERRARI, M.; OSBURN, B. I.; FRIGERI, F.; BARRECA, F.; TAGLIATI, S.; CUTERI, V. The use of a non-spcific defence mechanism inducer in calves exposed to bovine herpesvirus-1 infection: preliminary trials. Comparative Immunology, Microbiology and Infectious Diseases, Oxford, v.18, n.2, p.85-91, 1994.

A non-specific defence inducer in preventing clinical signs of infectious bovine rhinotracheitis in calves. Comparative Immunology, Microbiology and Infectious Diseases, Oxford, v.19, n.3, p.163-169, 1996.
CASTRUCCI, G.; FRIGERI, F.; OSBURN, B. I.; FERRARI, M.; BARRECA, F.; SALVATORI, D. Further investigations on the efficacy of a non-specific defence inducer evaluated in calves exposed to infectious bovine rhinotracheitis virus. Comparative Immunology, Microbiology and Infectious Diseases, Oxford, v.21, n.2, p.155-163, Apr.1998.

CASTRUCCI, G.; OSBURN, B. I.; FRIGERI, F.; FERRARI, M.; SALVATORI, D.; LO DICO, M.; BARRECA, F. The use of immunomodulators in the control of infectius bovine rhinotracheitis. Comparative Immunology, Microbiology and Infectious Diseases, Oxford, v.23, n.3, p.91-97, Jul. 2000.

CHAVALI, S. R.; BARTON, L. D.; CAMPBELL, J. B.Immunopotentiation by orally-administered Quillaja saponins: effects in mice vaccinated intraperitoneally against rabies. Clinical and Experimental Immunology, Oxford, v.74, n.3, p.339-343, Dez. 1988.

COMACK, S.; ALKEMADE, S.; ROGAN, D. Clinical study evaluating a purified mycobacterial cell wall extract for the treatment of equine respiratory disease. Equine Practice, Santa Barbara, v.13, n.8, 1991.

COX, W. I., Examining the immunological and hematopoietic properties of an immunostimulant. Veterinarni Medicina, Praha, v.83, p.424-428, 1988.

DAINES, R. A.; ARANEO, B. A. The development of effective vaccine adjuvants employing natural regulators of T-cell lymphokine production in vivo. In: ADES, E. W; REST, R. F.; MORSE, S. A. (Ed.). Microbial pathogenesis and immune response. Nova Yorque: Academy of Sciences, 1994. p.144-161.

DANILOV, L. L; MALTSEV, S. D.; DEEVA, A. V.; NAROVLYANSKY, A.. N.; SANIN, A. V.; OZHERELKOV, S. V.; PRONIN, A. V. Phosprenyl: a novel drug with antiviral and immunomodulatory activity. Archivum Immunologiae et Therapiae Experimentalis, Wroclaw, v.44, n.5-6, p.395400, 1996.

DAVIS, E.G.; RUSH, B. R.; BLECHA, F. Increases in citokine and antimicrobial peptide gene expression in horses by immunomodulation with Propionibacterium acnes. Veterinary Therapeutics, Yardley,v.4, n.1, p.5-11, 2003.

ELKINS, K. L.; RHINEHART-JONES, T. R.; STIBITZ, S.; CONOVER, J. S.; KLINMAN, D. M. Bacterial DNA containing $\mathrm{CpG}$ motifs stimulates lymphocyte-dependent protection of mice against lethal infection with intracellular bacteria. The Journal of Immunology, Baltimore, v.162, n.4, p.2291-2298, Feb. 1999.

FLAMINIO, M. J.; RUSH, B. R.; SHUMAN, W. Immunologic function in horses after non-specific immunostimulant administration. Veterinary Immunology and Immunopathology, Amsterdam, v.63, n.4, p.303-315, Jun. 1998. 
GLASGOW,L. A.; FISCHBACH, J.; BRYANT, S. M.; KERN, E. R. Immunomodulation of host resistance to experimental viral infections in mice: effects of Corynebacterium acnes, Corynebacterium parvum, and Bacille Calmette- Guérin. Journal of Infectious Diseases, Chicago, v.135, n.5, p.763770, May 1977.

GOMIS, S.; BABIUK, L.; ALLAN, B.; WILLSON, P.; WATERS, E.; AMBROSE, N.; HECKER, R.; POTTER, A. Protection of neonatal chicks against a lethal challenge of Escherichia coli using DNA containing cytosinephosphodiester-guanine motifs. Avian Diseases, Kennett Square, v.48, n.4, p.813-822, Dec. 2004.

HALL, H.; TEUSCHER, C.; URIE, P.; BODEN, B.; ROBISON, R. Induced regression of bovine pappilomas by intralesional immunotherapy. Therapeutic Immunology, Oxford, v.1, p.319-324, 1994.

HARTMANN, K.; BLOCK, A.; FERK, G.; BEER, B.; VOLLMAR, A.; LUTZ, H. Treatment of feline leukemia virus (FeLV) infection. Veterinary Immunology and Immunopathology, Amsterdam, v.69, n.1-2, p.111-113, Sep. 1999.

HARTMANN, K.; BLOCK, A.; FERK, G.; VOLLMAR, A.; GOLDBERG, M.; LUTZ, H. Treatment of feline leukemia virus-infected cats with paraimunity inducer. Veterinary Immunology and Immunopathology, Amsterdam, v.65, n.24, p.267-275, Oct. 1998.

KLINMAN, D. M.; CURRIE, D.; GURSEL, I.; VERTHELYI, D. Use of CpG oligodeoxynucleotide as immune adjuvants. Immunological Reviews, Copenhagen, v.199, p.201-216, 2004.

KNOTTENBELT, D. C.; KELLY, D. F. The diagnosis and treatment of periorbital sarcoid in the horse: 455 cases from 1947 to 1999. Veterinary Ophthalmology, Oxford, v.3, n.2-3, p.169-171, 2000.

KURATA, K.; IWATA, A.; MASUDA, K.; SAKAGUCHI, M.; OHNO, K; TSUJIMOTO, H. Identification of CpG oligodeoxynucleotide sequences that induce IFN-3 production in canine peripheral blood mononuclear cells. Veterinary Immunology and Immunopathology, Amsterdam, v.102, n.4, p.441-450, Dec. 2004.

KYRIAKIS, S. C.; TZIKA, E. D.; LYRAS, D. N.; TSINAS, A. C.; SAOULIDIS, K.; SARRIS, K. Effect of an inactivated Parapoxvirus based immunomodulator (baypamun) on post weaning diarrhea syndrome and wasting pig syndrome of piglets. Research in Veterinary Science, London, v.64, n.3, p.187-190, May/Jun. 1998.

LABRO, M. T. Antibacterial agents-phagocytes: new concepts for old immunomodulation. International Journal of Antimicrobial Agents, Amsterdam, v.10, n.1, p.11-21, Apr. 1998.
LIN, H. X.; GONTIER, C.; SARON, M. F.; PERRIN, P. A new immunostimulatory complex (PICKCa) in experimental rabies: antiviral and adjuvant effects. Archives of Virology, New York, v.131, n.3-4, p.307-319, 1993.

LOWRY, H. H.; HE, H.; LOWRY, V. K.; SWAGGERRTY, C. L.; FERRO, P. J.; KOGUT, M. H. In vitro activation of chicken leucocytes and in vivo protection agains Salmonella enteritidis organ invasión and peritoneal S. enteritidis infection-induced mortality in neonatal chickens by immunistimulatory $\mathrm{CpG}$ oligodeoxynucleotide. FEMS Immunology and Medical Microbiology, Amsterdam, v.43, n.1, p.81-89, Jan. 2005.

MCCAW, D. L.; BOON, G. D.; JERGENS, A. E.; KERN, M. R.; BOWLES, M. H.; JOHNSON, J. C. Immunomodulation therapy for feline leukemia virus infection. Journal of the American Animal Hospital Association, Lakewood, v.37, n.4, p.356-363, Jul./Aug. 2001.

MEGID, J.; DIAS JUNIOR, J. G.; AGUIAR, D. M.; NARDI JÚNIOR, G.; SILVA, W. B.; RIBEIRO, M. G. Tratamento da papilomatose canina com Propionibacterium acnes. Arquivo Brasileiro de Medicina Veterinária e Zootecnia, Belo Horizonte, v.53, n.5, p.574-576, 2001.

MEGID, J.; PERACOLLI, M. T. S.; CURI, P. R.; ZANETTI, C. R.; CABRERA, W. H.; VASSAO, R.; ITO, F. H. Effect of vaccination and the immunomodulators "bacillus of Calmette-Guérin, Avridine and Propionibacterium acnes on rabies in mice. Comparative Immunology Microbiology and Infectious Diseases, Oxford, v.21, n.4, p.305-318, Oct.1998.

PANANGALA, V. S.; HAYNES, T. B.; SCHULTZ, R. D.; MITRA, A. Immunomodulation with killed Propionibacterium acnes in guinea pigs simultaneosly vaccinates with Brucella abortus strain 19. Veterinary Immunology and Immunopathology, Amsterdam, v.13, n.12, p.71-84, 1986.

SANTOS, C. D.; TOLDO, M. P. A.; PRADO JÚNIOR, J. C. Trypanossoma cruzi: The effects of dehydroepiandrosterone (DHEA) treatment during experimental infection. Acta Tropica, Basel, v.95, p.109$115,2005$.

SPINOSA, H. S. Farmacologia aplicada à medicina veterinária. 2.ed. Rio de Janeiro: Guanabara Koogan, 1999.

TIZARD, I. R. Imunologia veterinária. 6.ed. São Paulo: Roca, 2002.

VAN DER STEDE, Y.; COX, E.; VERDONCK, F.; VANCAENEGHEM, S.; GODDEERIS, B. M.Reduced faecal excretion of of F4+- E.coli by intramuscular immunization of suckling piglets by the addition of 1a,25(OH)2D3 or CpG- oligodeoxynucleotides. Vaccine, Kidlinton, v.21, n.910, p.1023-1032, Feb. 2003. 
VAN KAMPEN, K. R. Imunotherapy and Cytokines. Seminars in Veterinary Medicine and Surgery (Small Animal), Orlando, v.12, n.3, p.186-192, Aug.1997.

WEISS, R.C.; COX, N. R. Effect of interferon or Propionibacterium acnes on the course of experimentally induced feline infectious peritonitis in specific-pathogenfree and random-source cats. American Journal of Veterinary Research, Schaumburg, v.51, n.5, p.726-733, May 1990.

WINNICKA, A.; KLUCINSKI, W.; KAWIAK, J.; HOSER, G.; SIKORA, J. Effect of Baypamun ${ }^{\circledR}$ on blood leucocytes in normal an dexamethasone treated goats. Journal of Veterinary Medicine Series A, v.47, n.7, p.385-394, Sep. 2000.
WINTERS, A. L; BAGGETT, D. W.; LEE, J. D.; SLOAN, G. L.; LEMMON, R. D.; STINSON, R. S. Immunomodulation by Bordetella pertussis: antiviral effects. Developments in Biological Standardization, Basel, v.61, p.233-240, 1985.

ZIMMERMANN, S.; EGETER, O.; HAUSMANN, S.; LIPFORD, G. B.; ROCKEN, M.; WAGNER, H.; HEEG, K. Cutting edge: $\mathrm{CpG}$ oligodeoxynucleotides trigger protective and curative Th1 responses in lethal murine leishmaniasis. The Journal of Immunology, New York, v.160, n.8, p.3627-3630, Apr. 1998. 